\title{
Perancangan Media Pembelajaran Kimia Tentang Struktur Atom Berbasis Multimedia
}

\author{
Havid Syafwan', Pristiyanilicia Putri' ${ }^{2}$, Mariana ${ }^{3}$ \\ 1,3Prodi D3 Manajemen Informatika STMIK Royal Kisaran \\ 2Prodi SI Sistem Informasi STMIK Royal Kisaran \\ Jl. Prof.H.M Yamin No.173, Telp (0623)41079 \\ email: havid_syafwan@yahoo.com
}

\begin{abstract}
At present, Information and Communication Technology (ICT) has developed so rapidly in various aspects of life, one of which is in the field of education. Computers are media that support the development of ICTs and as interactive multimedia-based learning facilities, so that users can absorb information quickly and efficiently. In addition, a new and more interesting and effective system of teaching and learning is needed which is very supportive in the quality and quality of teaching and learning. This research discusses the interactive learning media in chemistry lessons on atomic structure which is one of the teaching solutions for chemistry lessons for students in an easier and more enjoyable way. The problem faced here is how to design interactive learning media as one of the alternative learning media supporting the teaching and learning process in schools that is easily understood materially and makes it easier for students to see things or objects that are real. The form of this research is an interactive multimedia learning application using Adobe Flash CS6. The overall results achieved are expected to provide more value to help educators in providing material that is interesting, fun and easy to understand to improve student achievement.
\end{abstract}

Keywords: Learning Media, Multimedia, Adobe Flash CS6, Chemistry Lessons, Atomic Structures

Abstrak-Pada saat sekarang ini Teknologi Informasi dan Komunikasi (TIK) telah berkembang begitu pesat diberbagai aspek kehidupan, salah satunya di bidang pendidikan. Komputer merupakan media yang mendukung perkembangan TIK dan sebagai sarana pembelajaran berbasis multimedia yang bersifat interaktif, sehingga para pengguna dapat menyerap informasi dengan cepat dan efisien. Selain itu juga dibutuhkannya suatu sistem cara belajar mengajar yang baru yang lebih menarik dan efektif yang sangat mendukung dalam kualitas serta mutu belajar mengajar. Penelitian ini membahas mengenai media pembelajaran interaktif pada pelajaran kimia tentang struktur atom yang menjadi salah satu solusi pengajaran pada pelajaran kimia untuk siswa-siswi dengan cara yang lebih mudah dan menyenangkan. Permasalahan yang dihadapi disini adalah bagaimana merancang media pembelajaran interaktif tersebut sebagai salah satu media pembelajaran alternatif pendukung proses belajar mengajar disekolah yang mudah dipahami secara materi dan memudahkan siswa untuk melihat sesuatu atau objek yang nyata. Wujud dari penelitian ini adalah sebuah Aplikasi multimedia pembelajaran interaktif menggunakan Adobe Flash CS6. Dari keseluruhan hasil yang dicapai diharapkan memberikan nilai lebih untuk membantu para pendidik dalam memberikan materi yang menarik, menyenangkan dan mudah dipahami untuk meningkatkan prestasi belajar siswa-siswi.

Kata kunci: Media Pembelajaran, Multimedia, Adobe Flash CS6, Pelajaran Kimia, Struktur Atom

\section{PENDAHULUAN}


Teknologi informasi dan komunikasi saat ini telah berkembang begitu pesat di berbagai aspek kehidupan. Salah satunya adalah teknologi informasi berbasis multimedia yang diharapkan bisa memberikan peranan penting dalam proses menyalurkan informasi. Informasi tersebut disebarluaskan melalui banyak cara, salah satunya yaitu dengan aplikasi multimedia, khususnya dibidang pendidikan. Ketika kita membahas tentang mutu pendidikan, maka hal tersebut tidak terlepas dari kegiatan belajar mengajar. Pada sistem pendidikan, siswa-siswi umumnya akan diberikan materi oleh para pengajar dari buku teks atau buku paket yang diperoleh mereka, sehingga pemahaman yang didapat pun kurang maksimal dan minat siswa untuk belajar juga rendah. Metode pendidikan yang dulunya kurang interaktif dirasa tidak kompetitif lagi, oleh karena itu dibutuhkan pendidikan modern yang berarti menghargai siswa-siswi sebagai individu merdeka. Setiap siswa berhak menjadi pusat aktivitas pembelajaran. Bukan hanya pembelajaran dalam konteks tekstual yang dibatasi oleh sebuah ruang bernama kelas. Akan tetapi, pembelajaran yang juga berkaitan dengan eksistensi diri di dalam kehidupan sehari-hari. Dengan majunya Teknologi Informasi saat ini, maka dapat memberikan perubahan dibidang pendidikan. Dengan munculnya media pembelajaran yang inovatif dapat memberikan motivasi tersendiri bagi para siswa dalam belajar. Salah satunya adalah dengan memanfaatkan teknologi multimedia dalam suatu pembelajaran. Multimedia atau teknologi terpadu merupakan cara untuk memproduksi dan menyampaikan bahan belajar dengan memadukan beberapa jenis media yang dikendalikan oleh komputer. Keistimewaan yang ditampilkan oleh teknologi multimedia yaitu adanya interaksi peserta didik yang tinggi dengan berbagai macam sumber belajar. Program multimedia interaktif merupakan salah satu media pembelajaran yang berbasis komputer. Media ini menggabungkan dan mensinergikan semua media yang terdiri dari teks, grafis, foto, animasi, musik, narasi, suara, dan interaksi yang diprogram berdasarkan teori dan prinsip-prinsip pembelajaran. Pelajaran kimia merupakan salah satu pelajaran yang cukup rumit untuk dipahami terutama dalam memahami dan menghafal struktur atom. Selama ini, pembelajaran mengenai materi struktur atom di sekolah hanya didapat melalui buku bacaan kemudian dijelaskan oleh para pengajar dalam pertemuan yang diajarkan setiap satu minggu sekali. Sehingga membuat para siswa/siswi merasa bosan, mengantuk, dan jenuh menghadapi materi tersebut. Berdasarkan pada masalah di atas, maka penulis mencoba membuat sebuah media pembelajaran kimia tentang struktur atom berbasis multimedia untuk membantu para siswa dalam memahami materi tersebut. Permasalahan yang ada dalam penelitian ini adalah bagaimana merancang media pembelajaran interaktif untuk pembelajaran struktur atom kimia kepada para siswa dan bagaimana mengkolaborasikan elemen teknologi multimedia yang ada menjadi satu animasi yang aplikatif dan user friendly. Adapun tujuan dari penelitian ini agar dapat merancang sebuah media pembelajaran kimia tentang struktur atom bagi para siswa dan dapat mengkolaborasikan elemen multimedia yang ada menjadi satu animasi yang aplikatif dan user friendly.

\section{METODOLOGI PENELITIAN} 2.1 Perancangan 
Dalam Kamus Besar Bahasa Indonesia perancangan adalah "Proses, cara, pembuatan dalam merancang"[3]. Sedangkan menurut sumber yang lain [1], Komputer Indonesia bahwasannya "Perancangan adalah suatu kegiatan yang memiliki tujuan untuk mendesain sistem baru yang dapat menyelesaikan masalahmasalah yang dihadapi perusahaan yang diperoleh dari pemilihan alternatif sistem yang terbaik".

\subsection{Animasi Interaktif}

Kata animasi berasal dari bahasa latin anima yang secara harfiah berarti 'dihidupkan', Secara lebih khusus pengertian animasi adalah "satu proses menghidupkan atau memberikan gambar yang dapat bergerak kepada suatu yang berawal static agar terlihat hidup dan dinamik. Dalam Kamus Besar Bahasa Indonesia animasi adalah "acara televisi yang berbentuk rangkaian lukisan atau gambar yg digerakkan secara mekanik elektronis sehingga tampak di layar menjadi bergerak"[3]. Sedangkan interaktif adalah "bersifat saling melakukan aksi, antar-hubungan, saling aktif". Seels dan Glasgow menyatakan bahwa "animasi interaktif adalah proses penyampaian yang menyajikan dalam bentuk video, atau gambar yang dapat bergerak dengan pengendalian yang dilakukan oleh komputer kepada para penonton dengan tidak hanya menonton namun juga dengan adanya audio yang dapat didengar, sekaligus efek grafik yang ditimbulkan untuk menarik respon yang aktif dalan penyajiannya.

Selanjutnya bahwa "media belajar/ pembelajaran adalah komponen sumber belajar atau wahana fisik yang mengandung materi instruksional di lingkungan siswa yang dapat merangsang siswa untuk belajar" [1].

\subsection{Multimedia}

\subsubsection{Definisi Multimedia}

Didalam [4] definisi multimedia adalah "kombinasi dari komputer dan video atau Multimedia secara umum merupakan kombinasi tiga elemen, yaitu suara, gambar, teks atau Multimedia adalah kombinasi dari paling sedikit dua media input atau output dari data, media ini dapat audio (suara, musik), animasi, video, teks, grafik dan gambar atau Multimedia merupakan alat yang dapat menciptakan presentasi yang dinamis dan interaktif yang mengkombinasikan teks, grafik, animasi, audio dan gambar video".

Definisi yang lain dari multimedia, yaitu dengan mendapatkannya dalam konteks, multimedia adalah pemanfaatan komputer untuk membuat dan menggabungkan teks, grafik, audio, gambar bergerak (video dan animasi) dengan menggabungkan link dan tool yang memungkinkan pemakai melakukan navigasi, berinteraksi, berkreasi dan berkomunikasi.

Dalam definisi ini terkandung empat komponen penting multimedia. Pertama, harus ada komputer yang mengkoordinasi apa yang dilihat dan didengar, yang berinteraksi dengan kita. Kedua harus ada link atau koneksi yang menghubungkan kita dengan informasi. Ketiga, harus ada alat navigasi yang memandu kita, menjelajah jaringan informasi yang saling terhubung. Keempat, multimedia menyediakan tempat kepada kita untuk mengumpulkan, memproses, dan mengkomunikasikan informasi dan ide kita sendiri. 


\subsubsection{Objek Multimedia}

Terdapat "enam komponen multimedia, yaitu teks, grafis, bunyi, video, animasi, dan software". Sebagai berikut :

a. Teks

Bentuk data multimedia yang paling mudah dan disimpan dan dikendalikan adalah teks. Teks merupakan yang paling dekat dengan kita dan paling banyak kita lihat. Teks dapat membentuk kata, surat atau narasi dalam multimedia yang menyajikan bahasa kita. Kebutuhan teks bergantung pada kegunaan aplikasi multimedia. Misalnya game membutuhkan teks lebih sedikit. Sedangkan ensiklopedi membutuhkan teks lebih banyak. Secara umum ada empat macam teks, yaitu teks cetak, teks hasil scan, teks elektronis, dan hypertext.

b. Grafis

Grafis seringkali muncul sebagai latar belakang suatu teks untuk menghadirkan kerangka yang mempermanis teks. Gambar juga dapat berfungsi sebagai ikon, yang bila dipadu dengan teks, menunjukkan berbagai opsi yang bisa dipilih, atau gambar juga dapat muncul secara full screen menggantikan teks. Grafis sering digunakan karena lebih menarik perhatian.

c. Suara

Ada tiga belas jenis objek bunyi yang dapat digunakan dalam produksi multimedia, yakni format wave form audio, aiff, dat, ibk, mod, rmi, sbi, snd, voc, $a u$, MIDI sound track, compact disc audio, dan MP3 file.

d. Video

"Video adalah teknologi pemrosesan gambar sinyal elektronik yang mewakilkan gambar bergerak" [7]. Video menyediakan sumber daya yang kaya dan hidup bagi aplikasi multimedia. Ada empat macam video yang dapat digunakan sebagai objek link dalam aplikasi multimedia, yaitu live video feeds, videotape, videodisc, dan digital video.

e. Animasi dalam Multimedia

Animasi merupakan penggunaan komputer untuk menciptakan gerak pada layar. Ada sembilan macam animasi, yaitu animasi sel, animasi frame, animasi sprite, animasi lintasan, animasi spline, animasi vektor, animasi karakter, animasi computational, dan morphing.

f. Software dan Data

Salah satu konsep paling ampuh dalam multimedia adalah ketergantungan serentak yang dapat dicapai dengan menciptakan link keberbagai dokumen dan dataset. Saat pemakai memicu satu link kesuatu dokumen word processor, seperti file .doc, di Microsoft Word, maka komputer akan secara otomatis meluncurkan aplikasi perangkat lunak (pada contoh ini MS.Word) dan menggunakannya untuk menampilkan dokumen yang dimaksud. Begitu pula, sebuah link kesebuah file .xls di Excel untuk menampilkan spreadsheet tersebut.

\section{HASIL DAN PEMBAHASAN}

3.1 Membuat Aplikasi 
Dalam membuat media pembelajaran ini dibagi menjadi dua proses, yaitu proses pengumpulan bahan/materi dan proses editing dengan menggunakan beberapa software.

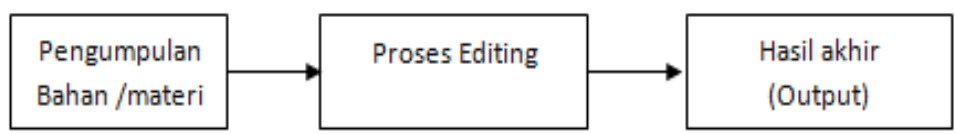

Gambar 1. Proses Produksi Aplikasi.

\subsubsection{Pengumpulan Materi}

Materi yang dimaksud adalah gambar-gambar struktur atom serta definisi dan penjelasannya untuk pembuatan aplikasi ini.

\subsubsection{Proses Editing}

Didalam proses pembuatan media pembelajaran ini, editing yang dilakukan tidak hanya memerlukan satu perangkat lunak, tetapi dilakukan dengan beberapa perangkat lunak. Untuk lebih jelasnya, proses pembuatan/editing media pembelajaran tersebut dapat dilihat pada gambar 2 berikut.

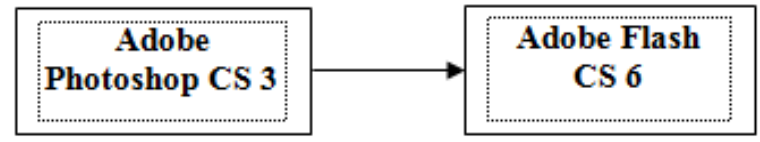

Gambar 2. Proses Editing

a. Pengeditan Aplikasi dengan Adobe Photoshop CS3

Dalam proses editing ini background dan tampilan-tampilan aplikasi ini didesain, kemudian dilanjutkan dengan proses layouting atau mendesain tata letak materi.

b. Pengeditan Aplikasi dengan Adobe Flash CS6

Adobe Flash CS6 digunakan untuk menyusun semua materi yang telash disiapkan menjadi file multimedia Flash. Pembuatan media pembelajaran ini memerlukan satu file utama yaitu "Aplikasi Utama.swf", dan folder sound (tempat meletakkan file yang berhubungan dengan suara atau musik). Berikut proses pembuatan Aplikasi Utama.swf:

1. membuat file baru dari menu "File - New", memilih Flash file (ActionSript 2.0). save As "Aplikasi Utama.fla" ini pada folder yang sama file - file materi pendukung lainnya.

2. Membuat ukuran lembar kerja pada menu "properties" menjadi width $600 p x$ hight $400 p x$.

3. Membuat baground dengan cara memilih menu " file - import - import to library" dan pilih beberapa gambar yang sudah disediakan untuk dijadikan latar belakang pada media pembelajaran ini. Kemudian masukkan gambar dari "Library" kedalam timeline lembar kerja dengan cara men-drag.

4. Membuat layout materi, layout materi ini berisikan pengertian atom, modelmodel atom, dan tabel periodik. Membuatnya dengan cara memilih menu "file - import - import to library" dan pilih gambar sebagai latar belakang dan juga 
model - model atom yang sudah diimport untuk dijadikan isi materi pada media pembelajaran ini . Kemudian masukkan gambar dari "library" kedalam timeline lembar kerja dengan cara men-drag.

5. Memasukkan musik background dan rekaman suara yang dijadikan sebagai pengisi suara pada bagian materi. Memasukkan musik background dengan cara membuat terlebih dahulu layer bernama "sound, selanjutnya pilih menu "file - import - import to library" dan pilih sebuah file musik mp3 yang sudah disediakan untuk dijadikan musik background pada media pembelajaran ini. Kemudian masukkan musik mp3 tersebut dari "library" kedalam layar "sound" didalam lembar kerja dengan cara men-drag dan pada library lakukan linkage agar mudah dalam penavigasian. Sama hal nya dengan memasukkan musik pada background, memasukkan rekaman suara dibagian materi dengan cara pilih menu "file - import - import to library" dan pilih file rekaman yang sudah disediakan untuk dijadikan pengisi suara pada bagian materi di media pembelajaran ini. Kemudian masukkan rekaman tersebut dari "library" kedalam layer "Timeline" didalam lembar kerja dengan cara men-drag.

6. Membuat contoh quis dapat diawali dengan membuat sebuah layer pada lembar kerja adobe flash tepatnya pada frame 1, kemudian dilanjuttkan dengan membuat sebuah judul dan input text untuk pengisian nama pengguna, dan di Timeline berikutnya berisi soal - soal seputar model model atom dan tabel periodik. Contoh quis ini berupa soal - soal pilihan ganda, setiap jawaban yang benar mendapat nilai 10 .

\subsection{Implementasi program}

Didalam melakukan pengimplementasian media pembelajaran berbasis multimedia dengan menggunakan adobe flash ini, perlu dilakukan uji coba kembali apakah setiap bagian-bagian atau komponen-komponen program tersebut dapat berjalan dengan baik sesuai yang dirancang atau tidak. Caranya dengan menekan pada keyboard "ctrl + enter". Berikut adalah tampilan disaat kita menjalankan aplikasi tersebut:

a. Halaman Menu Utama

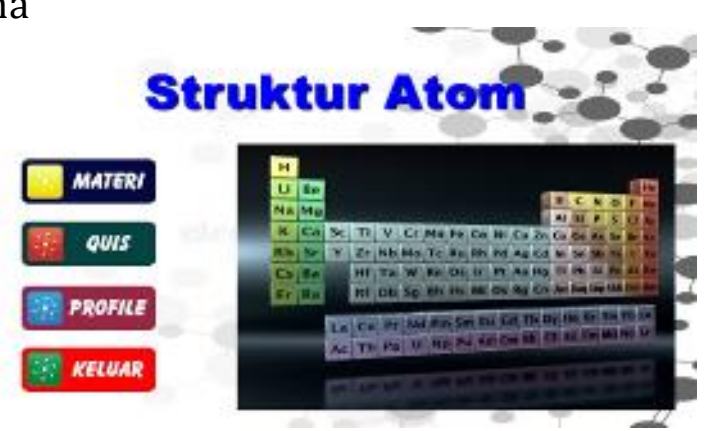

Gambar 3. Tampilan Halaman Menu Utama

b. Halaman Menu Materi 


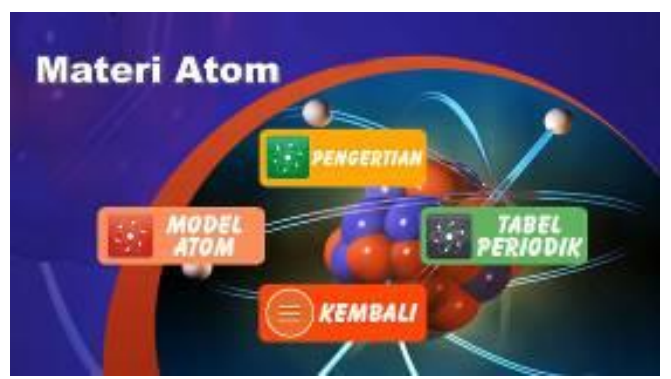

Gambar 4. Tampilan Halaman Menu Materi

c. Halaman Sub Menu Materi (Pengertian Atom)

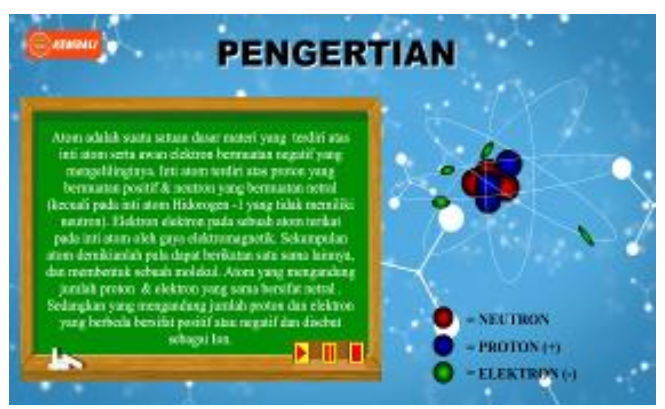

Gambar 5. Tampilan Halaman sub menu materi

d. Halaman Tabel Periodik

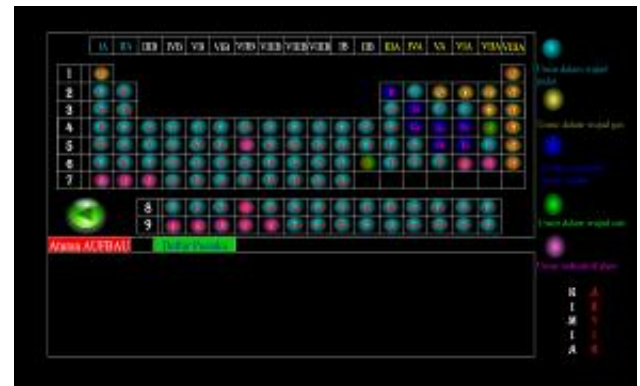

Gambar 6. Tampilan Halaman Tabel Periodik

e. Halaman Tampilan Quis

\section{KESIMPULAN}

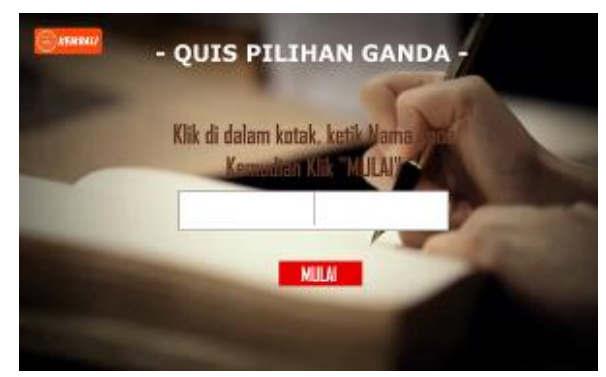

Gambar 7. Tampilan Halaman Quis 
Dari hasil penelitian tentang perancangan media pembelajaran kimia berbasis multimedia menggunakan Adobe Flash CS6 pada materi struktur atom, maka penulis dapat menyimpulkan hal-hal sebagai berikut :

a. Keuntungan pembelajaran dengan menggunakan media pembelajaran ini yaitu mudah dalam pemakaiannya sehingga dapat digunakan oleh pemakai pemula sekalipun. Karena terdapat menu utama yang sangat membantu pemakai (user).

b. Materi dibuat secara terstruktur, tanpa ada kesan terburu-buru dalam pemahaman materi karena pemakai dapat mengulangnya setiap saat sesuai keinginannya.

c. Dengan dibuatnya aplikasi media pembelajaran ini, akan memberikan kemudahan bagi pendidik sebagai alternatif baru dalam membantu menyajikan sebuah media pembelajaran yang membantu dalam proses belajar dan menjadi lebih menarik serta mudah dipahami.

\section{DAFTAR PUSTAKA}

[1] Arifin, Yuliani,S.Kom. MM., dkk. 2015. Digital Multimedia. Jakarta Barat : PT.Widia Inovasari Nusantara.

[2] Ariyus, Dony. 2009. Keamanan Multimedia. Yogyakarta : Andi.

[3] KBBI. 2008. Kamus Besar Bahasa Indonesia Cetakan Pertama Edisi IV. Jakarta : Gramedia.

[4] Suyanto, M. 2005. Multimedia : Alat Untuk Meningkatkan Keunggulan Bersaing. Yogyakarta : Andi.

[5] Sunyoto, Andi. 2010. Adobe Flash + XML : Rich Multimedia Application. Yogyakarta : Andi.

[6] Sukiman. 2011. Pengembangan Media Pembelajaran. Yogyakarta : PT. Pustaka Insan MADANI Persada.

[7] Wahana Komputer. 2012. Adobe Flash CS6. Yogyakarta : C.V Andi. 